\title{
The Role of Serum Cystatin C in the Early Detection of Contrast-Induced Nephropathy after Coronary Intervention
}

\author{
Al-Tu'ma FJ ${ }^{1}$, Dheyauldeen MH $^{1}$, Almukhtar MA $^{2}$, Al Jawad SY ${ }^{3}$ and Al-Saegh RM ${ }^{*}$ \\ ${ }^{1}$ Department of Biochemistry, College of Medicine, University of Kerbala/ Holy Kerbala, Iraq \\ ${ }^{2}$ Center of Radiology, Holy Kerbala, Iraq \\ ${ }^{3}$ Center of Cardiology, Holy Kerbala, Iraq \\ ${ }^{4}$ Department of Nephrology, College of Medicine, University of Kerbala/ Holy Kerbala, Iraq
}

Corresponding author: Riyadh Mohi Al-Saegh, Department of Nephrology, College of Medicine, University of Kerbala/Holy Kerbala, Iraq, Tel: 009647816113340; Email: riadabbood@gmail.com

Received date: Nov 10, 2017; Accepted date: Nov 15, 2017; Published date: Nov 21, 2017

Copyright: (c) 2017 Al-Tu'ma FJ, et al. This is an open-access article distributed under the terms of the Creative Commons Attribution License, which permits unrestricted use, distribution, and reproduction in any medium, provided the original author and source are credited.

\begin{abstract}
Objective: Contrast induced nephropathy is the most common complication for both coronary angiography and percutaneous coronary intervention. The aim of the present study is to investigate the role of serum cystatin $\mathrm{C}$ among patients undergoing coronary angiography for earlier detection of contrast induced nephropathy.

Materials and Methods: The study included 80 elective patients attending the cardiology center (48 males, 32 females). The study was conducted in cardiac catheterization unit at Al-Hussein Medical City/ Kerbala Health Directorate-Holy Kerbala, Iraq. Clinical examination and laboratory investigations were made before and 24 hours after angiography. These investigations include: serum creatinine, blood urea, estimated GFR and serum cystatin C.

Results: According to the definition, contrast induced nephropathy occurred in 19 patients $23.8 \%$ with grade 0 to 2 of renal dysfunction. There were significant increments in serum creatinine, cystatin C and eGFR after 24 hours of angiography/angioplasty procedures $p<0.001,0.01$ respectively. Receiver-operating characteristic analysis showed a higher area under the curve for creatinine $0.805(95 \% \mathrm{Cl}=0.688,0.921) \mathrm{p}=0.001,78.9 \%$ sensitivity and $60.7 \%$ specificity than serum cystatin $\mathrm{C} 0.777(95 \% \mathrm{Cl}=0.673-0.881) \mathrm{P}=0.001$ sensitivity $=78.9 \%$ and specificity $=64 \%$, a cutoff level of cystatin $\mathrm{C}>7 \mathrm{ng} / \mathrm{ml}$.
\end{abstract}

Conclusion: Cystatin C was a good biomarker for earlier diagnosis of contrast induced nephropathy when compared with blood urea and eGFR.

Keywords: Cystatin C; Contrast-induced nephropathy; Coronary angiography; Percutaneous coronary intervention

\section{Introduction}

Contrast induced nephropathy (CIN) is an important cause of acute kidney injury, which contributes to the deaths during hospitalization and prolongs hospital stay [1]. CIN is a complication recognized in both coronary angiography (CAG) and percutaneous coronary intervention (PCI) [2]. CIN defined as an increase in serum creatinine of $0.5 \mathrm{mg} / \mathrm{dL}(44 \mu \mathrm{mol} / \mathrm{L})$ or a relative $25 \%$ increase from the baseline value and mostly during the period from 24 to 48 hours following intravascular administration of contrast media [3]. CIN will occur in $2 \%$ to $25 \%$ of patients undergoing angiography [4]. This form of nephropathy has become the third leading cause of acute kidney injury [5]. Several investigations have been discovered to be used in the diagnosis of CIN [6]. Some of biomarker are used for detection of renal function such as serum cystatin C [7]. Cystatin C is $13 \mathrm{kDa}$ nonglycosylated protein belongs to the superfamily of cysteine protease inhibitors. It consists of 120 amino acids and has two disulfide bonds. It is produced by all human cells almost at constant rate with its removal from the blood by glomerular filtration [8]. Its low molecular weight makes it freely filtered in the glomeruli and catabolized completely in the proximal tubules [9]. Cystatin $\mathrm{C}$ is less affected by gender, age, race and muscle mass than creatinine [10].

The aim of present study was to assess whether serum cystatin $\mathrm{C}$ could be used in diagnosis of CIN in patients undergoing elective CAG and/or PCI, 24 hours after the procedures.

\section{Materials and Methods}

This project was conducted at center of cardiology, coronary catheterization unit, Holy Kerbala city, Iraq and in the department of biochemistry, College of Medicine, University of Kerbala. The study started from November 2015 to October 2016. The study included (80) patients (48 males, 32 females) attending the coronary catheterization unit for CAG and PCI. The medical history of each patient was taken regarding age, gender, diabetes mellitus, type of treatment, history of renal disease, history of any other diseases and smoking status. Measurements of their height and weight were done to calculate their body mass index (BMI), blood pressure before and during angiography. CIN is defined in our study as an increase in serum creatinine of $0.5 \mathrm{mg} / \mathrm{dL}(44 \mu \mathrm{mol} / \mathrm{L})$, or a relative $25 \%$ increase from the baseline value after 24 hours following intravascular administration of contrast media. We divided our patients who got 
CIN into three groups according to the rising grade of their serum creatinine [11] as shown in Table 1:

\begin{tabular}{|l|l|}
\hline CIN grade & Change in serum creatinine $($ S. Cr) \\
\hline Grade 0 & S. Cr increase $<25 \%$ and $<0.5 \mathrm{mg} / \mathrm{dL}$ above baseline. \\
\hline Grade 1 & S. Cr increase $\geq 25 \%$ and $<0.5 \mathrm{mg} / \mathrm{dL}$ above baseline. \\
\hline Grade 2 & S. Cr increase $\geq 0.5 \mathrm{mg} / \mathrm{dL}$ above baseline. \\
\hline
\end{tabular}

Table 1: CIN severity grading system

Amount of contrast media used in each patient was recorded after the procedure. All patients involved in the study were given lowosmolar non-ionic contrast media Omnipaque (Iohexol) $(350 \mathrm{mg} / 1 \mathrm{ml}$, $844 \mathrm{mOsm} / \mathrm{l})$. Serum creatinine, blood urea, eGFR and serum cystatin $\mathrm{C}$ were assessed before and at 24 hours after administration of contrast media. serum cystatin C (Cosabio, China) was measured by enzymelinked immunosorbent (ELISA). Estimated GFR was calculated according to the modification of diet in renal disease (MDRD) equation: $0.741 \times 175 \times($ Serum Cr. $[\mathrm{mg} / \mathrm{dl}])-1.154 \times($ age [years])- 0.203 (if female $\times 0.742$ ) [12]. This study was approved by the ethical committees at College of Medicine, University of Kerbala, Department of Medicine and committee of cardiac angiographic unit, Kerbala, Cardiac Center- Kerbala Health Directorate/Holy Kerbala, Iraq.

\section{Statistical Analysis}

Statistical analyses were performed by using the statistical package for social sciences (SPSS) software for windows, version 21, IBM, USA, data of 80 patients entered and analyzed. Descriptive statistics were presented as mean \pm standard deviation for continuous variables. Categorical variables were expressed as frequency (No.), and percentages (\%). Data were analyzed by independent sample t-test. Categorical variables are expressed as percentages and analyzed by chisquare $\left(\mathrm{X}^{2}\right)$ or fisher exact test as appropriate. Receiver operating characteristic (ROC) curves and the area under the curve (AUC) were constructed to describe the performance of serum creatinine and serum cystatin $\mathrm{C}$ at 24 hours post-contrast media exposure, the sensitivity and specificity were calculated. The best cut-off values for biomarkers were chosen on the basis of maximum sensitivity and specificity. Probability $(\mathrm{P})$ value were considered significant when it is less than $0.05 \%$, and highly significant if it is less than $0.01 \%$.

\section{Results}

The study subjects included 80 patients, 48 of them (60\%) were males and 32 were females (40\%). With a mean age of $59.85 \pm 9.976$ and age range of 41-80 years. All patients underwent elective CAG or PCI. According to the presented data and to the definition CIN and its grading in our study, CIN occurred in 19 patients $23.8 \%$. The incidence of CIN was $0.0 \%(\mathrm{n}=0)$ in patients with serum creatinine increase $<25 \%$ above baseline. While incidence in those with serum creatinine increase $\geq 25 \%$ and $<0.5 \mathrm{mg} / \mathrm{dL}$ above baseline was $42.1 \%(\mathrm{n}=8)$ and $57.9 \%(\mathrm{n}=11)$ serum creatinine increase $\geq 0.5 \mathrm{mg} / \mathrm{dL}$ above baseline as shown in Figure 1.

Table 2 shows the changes in the concentrations of different biomarkers in both CIN and non-CIN groups. There were significant increment in serum levels of creatinine, eGFR and cystatin C after 24 hours of angiography/angioplasty procedures $\mathrm{p}<0.001, \quad 0.01$ respectively.

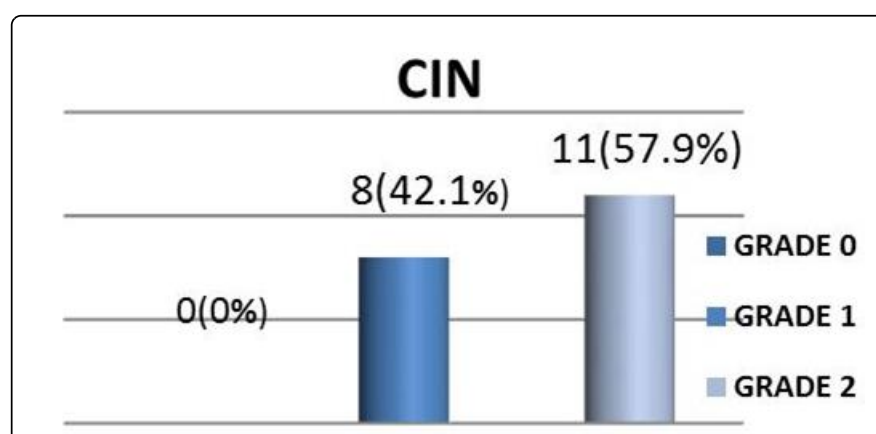

Figure 1: Incidence of CIN.

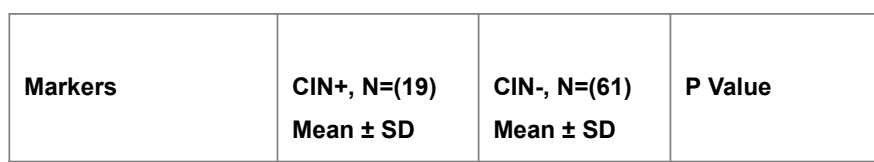

\begin{tabular}{|c|c|c|c|}
\hline \multicolumn{4}{|l|}{ S. Urea (mg/dl) } \\
\hline At 0 hours & $36.54 \pm 12.91$ & $31.64 \pm 7.03$ & $0.036^{*}$ \\
\hline After 24 hours & $50.20 \pm 25.06$ & $39.20 \pm 13.23$ & $0.015^{\star}$ \\
\hline \multicolumn{4}{|c|}{ S. Creatinine $(\mathrm{mg} / \mathrm{dl})$} \\
\hline At 0 hours & $0.77 \pm 0.22$ & $0.88 \pm 0.18$ & $0.037^{*}$ \\
\hline After 24 hours & $1.30 \pm 0.29$ & $0.98 \pm 0.19$ & $0.001^{* * *}$ \\
\hline
\end{tabular}

S. Cystatin C (ng/ml)

\begin{tabular}{|l|l|l|l|}
\hline At 0 hours & $4.66 \pm 5.31$ & $2.56 \pm 2.40$ & $0.018^{*}$ \\
\hline After 24 hours & $22.94 \pm 20.73$ & $9.46 \pm 10.25$ & $0.001^{* * *}$ \\
\hline eGFR & $102.47 \pm 43.04$ & $82.52 \pm 19.94$ & $0.006^{* *}$ \\
\hline At 0 hours & $56.57 \pm 18.42$ & $72.11 \pm 15.89$ & $0.001^{\text {** }}$ \\
\hline After 24 hours &
\end{tabular}

S- Serum, eGFR- estimate glomerular filtration rate, *- significant $p$ value at $0.05,{ }^{* *}-p$ value at $0.01,{ }^{* * *}-p$ value at 0.001

Table 2: Changes of serum and urinary markers between CIN and non-CIN groups.

\section{Receiver operating characteristics}

The result of receiver-operating characteristics analysis $(n=80$, $\mathrm{CIN}=19$ ) shown in the Figure 2 a higher area under the curve for serum creatinine was shown 0.805 ( $95 \% \mathrm{CI}=0.688,0.921) . \mathrm{p}=0.001$, $78.9 \%$ sensitivity and $60.7 \%$ specificity. Cut off $>1.06 \mathrm{mg} / \mathrm{dl}$. Area under the curve for serum cystatin C 0.777 (95\% CI=0.673, 0.881, $\mathrm{P}=0.001$ ). Sensitivity $=78.9 \%$ and specificity $=63.9 \%$, cut-off level of cystatin C>7 ng/ml. Area under the curve of eGFR $0.739(95 \%$ $\mathrm{CI}=0.595,0.882$ ), sensitivity $=73.7 \%$ and specificity $=62.3 \%$, cut-off value $<63 \mathrm{ml} / \mathrm{kg} / 1.73 \mathrm{~m}^{2}$. Area under the curve of urea $0.670(95 \%$ $\mathrm{CI}=0.525,0.816)$ sensitivity $63.2 \%$ and specificity $63.9 \%$ and cut-off value $>39 \mathrm{mg} / \mathrm{dl}$. 


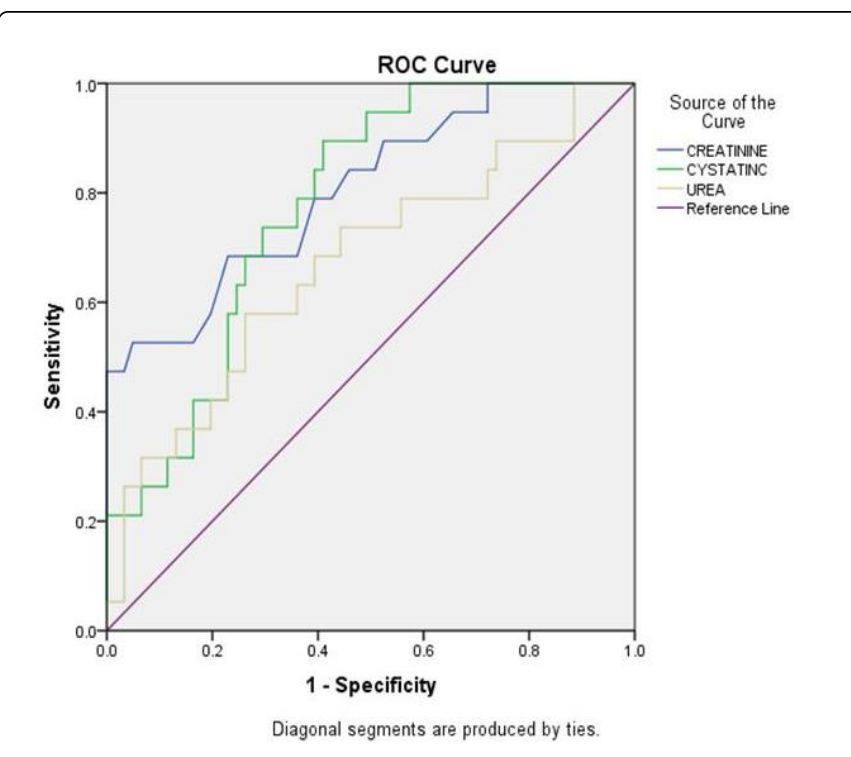

Figure 2: Receiver operating characteristics of serum creatinine and serum cystatain C. Area under the curve for serum creatinine was shown 0.805 (95\% CI $=0.688,0.921) .78 .9 \%$ sensitivity and $60.7 \%$ specificity. Area under the curve for serum cystatin C 0.777 (95\% $\mathrm{CI}=0.673,0.881)$ Sensitivity $=78.9 \%$ and specificity $=63.9 \%$, cut-off level of cystatin $\mathrm{C}>7 \mathrm{ng} / \mathrm{ml}$

\section{Discussion}

Acute kidney injury is an important topic because it has a significant impact on morbidity and mortality and hospital survival for patients. CIN is one of the main causes of AKI [13]. It is known that occurrence of CIN depends on the level of serum creatinine. According to the definition, CIN was defined as an increase of more than $25 \%$ from the baseline value of serum creatinine or an absolute increase of at least $0.5 \mathrm{mg} / \mathrm{dL}$ within 48 hours after the administration of contrast media [14].

In this study 80 patients who underwent elective PCI and CAG, the incidence of CIN was occurred in 19 (2 diagnostic and 17 therapeutic) patients $(23.8 \%) 24$ hours after the procedure. The results showed even patients with normal kidney function have a CIN after exposure to contrast media. Numerous studies have different results about percentage of development of CIN. Nassir in 2014 studied 42 patients with type 2 diabetes mellitus who developed CIN following PCI. He found the incidence of CIN, in diabetic patients approximately 2.6 times compared with non-diabetic 48 hours after the procedure [15]. A recent study was performed by Wang et al. that include 300 patients and found that only 29 patients of them developed of CIN [16]. Another report Alharazy et al. includes 100 patients with chronic kidney disease undergoing coronary angiography. The frequency of CIN in them was $11 \%$ and 1 patient required dialysis [17]. While Ribichini et al. studied 166 patients and he measured their serum creatinine and cystatin $\mathrm{C}$ at baseline and at 12, 24 and 48 hours after exposure to contrast media. He found that CIN occurred in 30 patients (18\%) [18]. A prospective study of consecutive 87 patients who underwent elective PCI and CAG, 31 patients had a moderate kidney disease, CIN occurred in 18 patients and was more frequent $42.0 \%$ [19]. The reason for the difference in incidence rates of CIN among different studies including this study may be due to differences in the definitions of CIN (absolute or relative) [20,21]. Another reason is the number of patient's disparity as some researchers have their specimen number which is very large and others have a small as well as some of the researchers depend on the occurrence of the disease at 48 hours after angiography other research were taken 24 hours. Also the type of angiographic procedure; PCI or CAG have effect on occurrence of $\mathrm{CIN}$. We found a higher incidence among PCI group with a $\mathrm{p}$ value of $<0.05$. This may be explained by a larger amount of contrast media we used in PCI group [22]. Therefore contrast volume $>100 \mathrm{ml}$ may be identified as a risk factor of occurrence CIN [23,24]. Although all patients involved in our study were given low-osmolar contrast agent Omnipaque (Iohexol) $350 \mathrm{mg} / 1 \mathrm{ml}$ ), osmality of 844 . Low-osmolar contrast media lead to a lower CIN incidence when compared to highosmolar contrast media. Nowadays there is no indication for use of high-osmolar contrast media and therefore this has been almost completely replaced by low-osmolar contrast media that has less effect on development of CIN [25]. Visipaque (iodixanol), is iso-osmolar contrast media (the same osmolarity of blood), non-ionic is a new one with less incidence of nephrotoxicity. Hydration is the best therapy to elimination of contrast from the body. It acts to dilute contrast media in both blood and tubular filtrate in addition to other treatment [26].

The results of the present study are in agreement with the most results obtained by others reports Kato et al. and Mehran et al. [19-27]. In present study was found a highly significant increment in serum creatinine and cystatin $C$ while decrease in eGFR 24 hours after angiography $(\mathrm{p}<0.001,0.01)$ when compared between two groups (CIN+, CIN-). This result is consistent with Wang et al., Liu et al. and Nozue et al. founded serum level of cystatin $\mathrm{C}$ is a reliable marker for $\mathrm{CIN}$ at 24 hours $\mathrm{p}<0.001$ and serum creatinine increased significantly at 48 hours, also study carried by Wacker-Gussmann et al. [16-31] found that cystatin $\mathrm{C}$ level and the cystatin $\mathrm{C} /$ creatinine ratio independently predict the risk of CIN in patients undergoing coronary angiography, but another study by Ribichini et al. [32] found a significant increase in serum cystatin $\mathrm{C}$ concentrations 12 hours earlier than serum creatinine, therefore a rise of serum cystatin $C$ at 12 hours from baseline was the earliest predictor of CIN than serum creatinine [18].

Cystatin $\mathrm{C}$ has been known to be a sensitive biomarker of renal dysfunction. Cystatin $\mathrm{C}$ has also been shown to be a good predictor of cardiovascular mortality and morbidity in various patients [33]. We conclude in this study that a rise of serum creatinine and cystatin $\mathrm{C}$ at 24 hours after angiography were good biomarker for early diagnosis of CIN than baseline values and better than urea and eGFR. This may be due to cystatin $\mathrm{C}$ which is produced by almost all human cells at a constant rate and have low molecular weight is freely filtered at the glomerulus and is completely catabolized by proximal tubules. In addition, cystatin $\mathrm{C}$ is less affected by age, gender and race while eGFR depended on age, gender and serum creatinine [34]. However, eGFR did not efficiently predict CIN. The fact that cystatin $\mathrm{C}$ is present in only extracellular fluid while creatinin is present in all body fluid can explain why cystatin $\mathrm{C}$ is an earlier marker of acute kidney injury. A significant problem with serum creatinine is that it is relatively insensitive to the rapid GFR changes seen in acute kidney injury, particularly in patients with normal baseline renal function. Elevations in serum creatinine typically take 2-3 days to reach the current diagnostic threshold following an acute renal insult, thus reducing its usefulness as earlier marker of acute kidney injury. However, early and minor incremental changes in serum creatinine may be a useful marker of CIN; recently clinical trial that investigated cystatin $\mathrm{C}$ have 
been proposed to specifically detect CIN within minutes to hours of the renal insult. Unfortunately, to date this biomarker has yet to progress beyond clinical research, there is a clear clinical need for large trial validation of its use in the early detection and intervention in acute kidney injury [11].

By receiver operating characteristic analysis showing a higher area under the curve for serum creatinine 0.805 (95\% CI $=0.688,0.921)$ sensitivity $=78.9 \%$ and $60.7 \%=$ specificity, area under the curve for serum cystatin C 0.777 (95\% CI=0.673, 0.881), Sensitivity $=78.9 \%$ and specificity $=63.9 \%$, cut-off level of cystatin C $>7 \mathrm{ng} / \mathrm{ml}$. Although several studies have revealed that serum cystatin $\mathrm{C}$ cut off level $>1.2$ or $>1.18$ or $>1.3 \mathrm{mg} / \mathrm{l}, 94 \%$ sensitivity and $48 \%$ specificity is more accurate for diagnostic CIN than serum creatinine [19-36]. While study obtained by Ribichini et al. found that absolute changes in serum creatinine proved more accurate than serum cystatin $\mathrm{C}$ for predicting $\mathrm{CIN}$ at an early stage 12 hours after angiography [18]. In the present study serum creatinine is still the standard marker for detecting temporal changes of renal function in individuals with established renal disease. Serum creatinine is an inexpensive marker use to measure kidney function compared to the other marker, whereas it is available in all laboratories and easily measured compared with other. Therefore creatinine still standard marker for diagnosis of kidney function.

\section{Conclusions}

Cystatin C is considered a good biomarker for early detection CIN after 24 hours angiography better than urea and eGFR. The cut-off level was $>7 \mathrm{ng} / \mathrm{ml}$. In present study CIN occurred in $23.8 \%$ of all patients. Even patients with normal kidney function have risk for development of CIN after CAG and PCI.

\section{References}

1. Palevsky PM (2009) Defining contrast-induced nephropathy. Clin J Am Soc Nephrol 4: 1151-1153.

2. Brown JR, Rezaee ME, Nichols EL, Marshall EJ, Siew ED, et al. (2016) Incidence and in-hospital mortality of Acute Kidney Injury (AKI) and dialysis-requiring AKI (AKI-D) after cardiac catheterization in the national inpatient sample. J Am Heart Assoc 5: e002739.

3. Cely CM, Schein RM, Quartin AA (2012) Risk of contrast induced nephropathy in the critically ill: A prospective case matched study. Crit Care 16: R67.

4. Solomon R, Dauerman HL (2010) Contrast-induced acute kidney injury Circulation 122: 2451-2455.

5. Tepel M, Aspelin P, Lameire N (2006) Contrast-induced nephropathy a clinical and evidence based approach. Circulation 113: 1799-1806.

6. Nikolsky E, Mehran R (2002) Understanding the consequences of contrast-induced nephropathy. Rev Cardiovasc Med 4: S10-8.

7. Malyszko J, Bachorzewska-Gajewska H, Poniatowski B, Malyszko JS, Dobrzycki S (2009) Urinary and serum biomarkers after cardiac catheterization in diabetic patients with stable angina and without severe chronic kidney disease. Ren Fail 31: 910-919.

8. Padhy M, Kaushik S, Girish MP, Mohapatra S, Shah S, et al. (2014) Serum neutrophil gelatinase associated lipocalin (NGAL) and cystatin C as early predictors of contrast-induced acute kidney injury in patients undergoing percutaneous coronary intervention. Clinica Chimica Acta. 435: 48-52.

9. Vaidya VS, Ferguson MA, Bonventre JV (2008) Biomarkers of acute kidney injury. Annu Rev Pharmacol Toxicol 48: 463-493.

10. Fan L, Inker LA, Rossert J, Froissart M, Rossing P, et al. (2014) Glomerular filtration rate estimation using cystatin $\mathrm{C}$ alone or combined with creatinine as a confirmatory test. Nephrol Dial Transplant 29: 1195-1203.
11. Rear R, Bell RM, Hausenloy DJ (2016) Contrast-induced nephropathy following angiography and cardiac interventions. Heart; heartjnl-2014

12. Levey AS, Stevens LA, Schmid CH, Zhang YL, Castro AF, et al. (2009) A new equation to estimate glomerular filtration rate. Annals of internal medicine 150: 604- 612.

13. Cronin RE (2010) Contrast-induced nephropathy: Pathogenesis and prevention. Pediatr Nephrol 25: 191-204.

14. Bartorelli AL, Marenzi G (2008) Contrast-induced nephropathy. J Interv Cardiol 21: 74-85.

15. Nassir SF (2014) Contrast induced nephropathy in diabetic and nondiabetic patients after coronary intervention. J Bab Uni 22.

16. Wang M, Zhang L, Yue R, You G, Zeng R (2016) Significance of cystatin C for early diagnosis of contrast-induced nephropathy in patients undergoing coronary angiography. Med Sci Monit 22: 2956-2961.

17. Alharazy SM, Kong N, Saidin R, Gafor AH, Maskon O, et al. (2014) Is It possible to prevent acute kidney injury in the patients who underwent contrast medium? Angiology 65: 225-226.

18. Ribichini F, Gambaro G, Graziani MS, Pighi M, Pesarini G, et al. (2012) Comparison of serum creatinine and cystatin $\mathrm{C}$ for early diagnosis of contrast-induced nephropathy after coronary angiography and interventions. Clin Chem 58: 458-464.

19. Kato K, Sato N, Yamamoto T, Iwasaki YK, Tanaka K, et al. (2008) Valuable markers for contrast-induced nephropathy in patients undergoing cardiac catheterization. Circ J 72: 1499-1505.

20. Mohammed NM, Mahfouz A, Achkar K, Rafie IM, Hajar R (2013) Contrast-induced nephropathy. Heart Views 14: 106-116.

21. Thomsen HS, Morcos SK, Erley CM, Grazioli L, Bonomo L, et al. (2008) The A CTIVE Trial: Comparison of the effects on renal function of iomeprol-400 and iodixanol-320 in patients with chronic kidney disease undergoing abdominal computed tomography. Investigative radiology. 43: $170-178$

22. Schiffrin EL, Lipman ML, Mann JF (2007) Chronic kidney disease effects on the cardiovascular system. Circulation 116: 85-97.

23. Fu N, Li X, Yang S, Chen Y, Li Q, et al. (2013) Risk score for the prediction of contrast-induced nephropathy in elderly patients undergoing percutaneous coronary intervention. Angiology 64: 188-194.

24. Seeliger E, Sendeski M, Rihal CS, Persson PB (2012) Contrast-induced kidney injury: Mechanisms, risk factors and prevention. Eur Heart J 33: 2007-2015.

25. Tanaga K, Tarao K, Nakamura Y, Inoue T, Jo K, et al. (2012) Percutaneous coronary intervention causes increase of serum cystatin $\mathrm{C}$ concentration even in the patients with a low risk of contrast-induced nephropathy. Cardiovasc Interv Ther 27: 168-173.

26. Chau CH, Williams DO (2016) Prevention of contrast-induced renal failure for the interventional cardiologist. Circulation: Cardiovasc Interven 9: e004122.

27. Mehran R, Aymong ED, Nikolsky E, Lasic Z, Iakovou I, et al. (2004) A simple risk score for prediction of contrast-induced nephropathy after percutaneous coronary intervention: Development and initial validation. J Am Coll Cardiol 44: 1393-1399.

28. Khanal S, Attallah N, Smith DE, Kline-Rogers E, Share D, et al. (2005) Statin therapy reduces contrast-induced nephropathy: An analysis of contemporary percutaneous interventions. Am J Med 118: 843-849.

29. Hashemi M, Kharazi A, Shahidi S (2005) Captopril for prevention of contrast induced nephropathy in patients undergoing coronary angioplasty: A double blind placebo controlled clinical trial. J Res Med Sci 10: 305-308.

30. Liu Y, Li H, Li LW, Tan N, Chen S, et al. (2016) Cystatin C and creatinine based definition of contrast-induced nephropathy after coronary angiography or percutaneous coronary intervention. J Am Coll Cardiol 67: 330 .

31. Nozue T, Michishita I, Mizuguchi I (2010) Predictive value of serum cystatin $\mathrm{C}, \beta 2$-microglobulin and urinary liver type fatty acid-binding protein on the development of contrast-induced nephropathy. Cardiovasc Interv Ther 25: 85-90. 
Citation: Al-Tu'ma FJ, Dheyauldeen MH, Almukhtar MA, Al Jawad SY, Al-Saegh RM (2017) The Role of Serum Cystatin C in the Early Detection of Contrast-Induced Nephropathy after Coronary Intervention. J Kidney 3: 154. doi:10.4172/2472-1220.1000154

Page 5 of 5

32. Wacker-Gußmann A, Bühren K, Schultheiss C, Braun SL, Page S (2014) Prediction of contrast-induced nephropathy in patients with serum creatinine levels in the upper normal range by cystatin C: A prospective study in 374 patients. AJR Am J Roentgenol 202: 452-458.

33. O'Seaghdha CM, Tin A, Yang Q, Katz R, Liu Y, et al. (2014) Association of a cystatin $\mathrm{C}$ gene variant with cystatin $\mathrm{C}$ levels, $\mathrm{CKD}$ and risk of incident cardiovascular disease and mortality. Am J Kidney Dis 63:16-22.

34. Kimmel M, Butscheid M, Brenner S, Kuhlmann U, Klotz U, et al. (2008) Improved estimation of glomerular filtration rate by serum cystatin $\mathrm{C}$ in preventing contrast induced nephropathy by $\mathrm{N}$-acetylcysteine or zincpreliminary results. Nephrol Dial Transplant 23: 1241-1245.

35. Briguori C, Visconti G, Rivera NV, Focaccio A, Golia B, et al. (2010) Cystatin $\mathrm{C}$ and contrast-induced acute kidney injury. Circulation 121: 2117-2122.

36. Ishibashi Y, Yamauchi M, Musha H, Mikami T, Kawasaki K, et al. (2010) Impact of contrast-induced nephropathy and cardiovascular events by serum cystatin $\mathrm{C}$ in renal insufficiency patients undergoing cardiac catheterization. Angiology 61: 724-730. 